Cases of infection with penicillinase producing Neisseria gonorrhoeae (PPNG) reported to Communicable Disease Surveillance Centre (CDSC) and St Thomas's Hospital

\begin{tabular}{|c|c|c|c|c|c|}
\hline Year & $\begin{array}{l}\text { Cases reported } \\
\text { to CDSC }\end{array}$ & $\begin{array}{c}\text { Cases of PPNG infection } \\
\text { at St Thomas's }\end{array}$ & $\begin{array}{l}\text { PPNG infection at St Thomas's } \\
\text { as \% of reports to CDSC }\end{array}$ & $\begin{array}{l}\text { Cases of gonorrhoea } \\
\text { at St Thomas's }\end{array}$ & $\begin{array}{l}\text { PPNG infection as \% of cases } \\
\text { of gonorrhoea at St Thomas's }\end{array}$ \\
\hline 1986 & 699 & 86 & $12 \cdot 3$ & 1413 & $6 \cdot 1$ \\
\hline 1987 & 379 & 32 & 8.4 & 867 & 3.7 \\
\hline 1988 & 289 & 25 & 8.7 & 588 & $4 \cdot 3$ \\
\hline 1989 & 246 & 59 & $24 \cdot 0$ & 907 & 6.5 \\
\hline 1990 & 269 & 54 & $20 \cdot 1$ & 1019 & $5 \cdot 3$ \\
\hline 1991 & 192 & 54 & $28 \cdot 1$ & 1026 & $5 \cdot 3$ \\
\hline
\end{tabular}

endemic in London, ${ }^{2}$ later analysis has proved this wrong (table) despite this organism's success elsewhere in the world.

Though under half of infections presenting to the genitourinary medicine clinic at this hospital have been acquired outside the United Kingdom, $90 \%$ of our patients infected with penicillinase producing Neisseria gonorrhoeae have a demonstrable foreign connection and "second generation" sexual transmission is rare. Far from thriving, penicillinase producing Neisseria gonorrhoeae seems to need constant topping up.

Heterosexual syphilis remains uncommon in the United Kingdom. After a clutch of cases in the late $1980 \mathrm{~s}^{3}$ we saw 22 cases of early infectious syphilis in heterosexuals during 1989-91, of which 14 were imported. Our figures are borne out nationally: a review of sexually transmitted diseases from the Communicable Disease Surveillance Centre stated that an increasing proportion of cases of infection with penicillinase producing Neisseria gonorrhoeae and syphilis were acquired abroad during 1981-90 while the overall numbers continued to decline. ${ }^{4}$ If both of these infections are examples of the likely future of HIV infection in heterosexuals in the United Kingdom there may be hope as neither has established itself in the heterosexual community.

Finally, is it a little disingenuous to write (correctly) that the Cox and Day reports "emphasised the great uncertainty concerning future heterosexual spread" when the Department of Health and others have tended to quote the more pessimistic predictions (of exponential spread) rather than quoting that "a lower scenario, also consistent with available data, is that little new transmission is taking place... and that only minor increases will be seen in the next few years in the yearly number of cases due to injecting drug use or heterosexual contact."

DAVID BARLOW

J SHERRARD

St Thomas's Hospital,

London SE1 7EH

1 Johnson AM. Home grown heterosexually acquired HIV infection. BMF 1992;304:1125-6. (2 May.)

2 Thin RN, Barlow D, Eykin S, Phillips I. Imported penicillinase producing Neisseria gonorrhoeae becomes endemic in producing Neisseria gonorrhoeae

3 Tang A, Barlow D. Resurgence of heterosexually acquired early syphilis in London. Lancet 1989;ii: 166-7.

4 Catchpole MA. Sexually transmitted diseases in England and Wales: 1981-1990. Communicable Disease Report 1992;Jan: R1-7.

5 Ades AE, Parker S, Berry T, Holland FJ, Davison CF, Cubitt D, et al. Prevalence of maternal HIV-1 infection in Thames regions: results from anonymous unlinked neonatal testing. Lancet 1991;337:1562-6.

6 Day NE, Anderson RM, Daykin CD, et al. Acquired immune deficiency syndrome in England and Wales to end 1993. Projections using data to end September 1989. Communicable Disease Report 1990; Jan:1-12.

AUTHOR'S REPLY, - David Barlow and J Sherrard comment on the current incidence of penicillinase producing Neisseria gonorrhoeae and syphilis in heterosexuals in the United Kingdom. My comments on the importation of sexually transmitted diseases were, however, clearly made in a historical context. Syphilis indeed thrived in heterosexuals in the United Kingdom and throughout Europe for nearly 500 years, resulting in a heavy toll in morbidity and mortality. Though accurate figures are hard to come by before formal notification began, surveys in 1914 suggested that
$12 \%$ of men and $7 \%$ of women in London suffered from acquired syphilis.' In 1925 reported cases of newly diagnosed syphilis in men and women exceeded 23000 a year. ${ }^{2}$ As Barlow and Sherrard indicate, infection with penicillinase producing Neisseria gonorrhoeae showed every sign of establishing itself as endemic in the early 1980s. In 1982 more than $70 \%$ of cases were acquired in the United Kingdom. ${ }^{3}$ Where infection with penicillinase producing Neisseria gonorrhoeae and syphilis part company from HIV infection is in the current availability of a highly effective cure. Rates of syphilis declined rapidly after the introduction of penicillin in the 1940s. Awareness of a rising incidence of infection with penicillinase producing Neisseria gonorrhoeae resulted in control measures, which included wider use of alternative antibiotics to penicillin and contact tracing through a comprehensive sexually transmitted disease service in the United Kingdom.

No effective cure yet exists for infection with HIV, the spread of which remains determined by its biological properties and by sexual and drug injecting behaviour patterns. Comparisons between the future prevalence of HIV and the current incidence of infection with penicillinase producing Neisseria gonorrhoeae and of syphilis are therefore unhelpful. In discussing the importation of sexually transmitted disease I had hoped to help readers take a longer term view of the problem and to consider the lessons of history.

Finally, Barlow and Sherrard reiterate the point that I made in my editorial that the Cox and Day reports emphasise uncertainty and present various projections consistent with the available data over the relatively short period of four years. In an attempt to put a balanced scientific view of heterosexually acquired HIV infection I deliberately referred to the official predictions of future spread and not to any secondary sources which have chosen to present selectively the extremes of the range of feasible scenarios discussed in these reports.

ANNE M JOHNSON

Academic Department of Genitourinary Medicine,

University College and Middlesex School of Medicine,

London WIN 8 AA

1 Adler MW. The terrible peril: a historical perspective on the nereal diseases. BMF 1980;281:206-11.

2 Academic Department of Genitourinary Medicine of Middlesex Hospital Medical School, Communicable Surveillance Centre, Communicable Diseases (Scotland) Unit. Sexually transmitred disease surveillance, 1978. BM7 1979;ii:1375-6.

3 Public Health Laboratory Service Communicable Disease Surveillance Centre, Communicable Diseases (Scotland) Unit, Academic Department of Genitourinary Medicine of Middlesex Hospital Medical School. Penicillinase-producing Neisseria gonorrhoeae in Britain 1982. BMJ 1983;286:1628-9.

\section{Treatment of allergy}

EDITOR, - The title of a recent news item by Luisa Dillner- "Alternative allergy treatments need clinical trials"- was slightly misleading since the second paragraph of the article was concerned with Professor Stephen Holgate's statements on the competence of certain doctors to treat allergy. ${ }^{1} \mathrm{He}$ is reported as saying, "We haven't recognised the importance of training people to treat allergy. We base our referral systems on organs and not on disease processes. . . Ophthalmologists and ENT surgeons see a lot of people with problems due to allergy but have no training in treating it." We believe that these comments are critical of the present systems of referral, as well as postgraduate training, and take issue with them.

Presentation is symptom based, and the subsequent assessment should result in diagnosis. Although patients may make an attempt at diagnosis, they rarely enter the clinic saying, for example, "I have a type one hypersensitivity to dust mite faeces." Until this enlightened state of affairs occurs patients with nasal allergy may present with various symptoms identical with those of other nasal and sinus conditions. The specialist has to be able to exclude not only the common conditions but also the rare ones that may cause symptoms. Part of this process entails examining the nose-few people outside the specialty of otolaryngology can do this effectively.

Though no courses are devoted exclusively to allergy, its importance is well recognised in our specialty. One of us has organised courses in practical rhinology which started as far back as 1984, with lecturers including basic scientists, allergists, chest physicians, and otolaryngologists. Similar courses are run regularly nationwide. Candidates for the final FRCS in otolaryngology are expected to understand allergy and its treatment.

We disagree with the idea that patients take to alternative treatment solely because doctors have failed them because they do not know how to treat allergy. The treatment itself may be unacceptable. People turn to alternative therapy for many reasons besides the failings of doctors or their treatments. They need mystery, magic, and ritual, and nowhere is this better recognised than in the treatment of allergy by some allergists, particularly in the United States.

We, and probably many other otolaryngologists and ophthalmologists, believe that the correct and enlightened approach is the involvement of interested practitioners in the treatment of allergic diseases. The picture in Britain is not nearly as dark as that painted by Dillner.

ADRIAN DRAKE-LEF SCOTT STEVENSON

Ear, Nose, and Throat Department,

Queen Elizabeth Hospital,

Birmingham B15 2TH

Dillner L. Alternative allergy treatments need clinical trials.

BMF 1992;304: 1003. (18 April.)

\section{Cardiac arrest associated with flumazenil}

EDIToR,--In their drug point Yeshayahu Katz and colleagues report on a 60 year old man admitted with an extensive acute anterior wall myocardia infarction. ' Adverse prognostic features included cardiac failure complicated by pulmonary oedema (serious enough to require mechanical ventilation) and haemodynamic instability associated with ventricular arrhythmia. The patient began to resist ventilation but was still drowsy, an effect considered to be secondary to the sedative action of diazepam. Details of the patient's cardiopulmonary status at this time are not provided. To facilitate weaning from the ventilator a total of $0.4 \mathrm{mg}$ of the specific benzodiazepine antagonist flumazenil was given intravenously. This was followed by a refractory ventricular arrhythmia, asystole, and death

The authors conclude that the fatal arrhythmia was due to a direct effect of flumazenil. They point out that this mode of action differs from that reported in earlier cases of death after flumazenil, in which the fatal event was a wearing off of antagonist activity. ${ }^{2}$

Kat $z$ and colleagues' statements and conclusions are misleading. In their quoted references the 